\title{
SIMULATIONS OF THE UNSTEADY FLOW THROUGH THE FASTRAC SUPERSONIC TURBINE
}

\author{
Lisa W. Griffin \\ Fluid Dynamics Analysis Branch \\ National Aeronautics and Space Administration \\ George C. Marshall Space Flight Center \\ Marshall Space Flight Center, AL \\ Daniel J. Dorney \\ Department of Mechanical Engineering \\ Virginia Commonwealth University \\ Richmond, VA
}

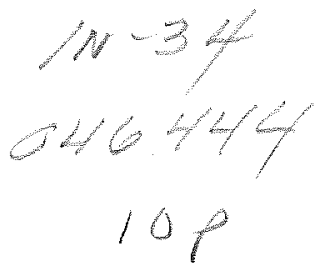

\begin{abstract}
Analysis of the unsteady aerodynamic environment in the Fastrac supersonic turbine is presented. Modal analysis of the turbine blades indicated possible resonance in crucial operating ranges of the turbopump. Unsteady computational fluid dynamics (CFD) analysis was conducted to support the aerodynamic and structural dynamic assessments of the turbine. Before beginning the analysis, two major problems with current unsteady analytical capabilities had to be addressed: modeling a straight centerline nozzle with the turbine blades and exit guide vanes (EGVs), and reducing run times significantly while maintaining physical accuracy. Modifications were made to the CFD code used in this study to allow the coupled nozzle/blade/EGV analysis and to incorporate Message Passing Interface (MPI) software. Because unsteadiness is a key issue for the Fastrac turbine [and future rocket engine turbines such as for the Reusable Launch Vehicle (RLV)], calculations were performed for two nozzle-to-blade axial gaps. Calculations were also performed for the nozzle alone, and the results were imposed as an inlet boundary condition for a blade/EGV calculation for the large gap case. These results are compared to the nozzle/blade/EGV results.
\end{abstract}

\section{NOMENCLATURE}

$\begin{array}{ll}a & \text { Speed of sound } \\ b & \text { Blade height } \\ c & \text { Axial Chord } \\ C_{p} & \text { Coefficient of pressure } \\ c_{p} & \text { Specific heat at constant pressure } \\ F, G, H & x, y, z \text { components of flux } \\ i & \text { Inviscid quantity } \\ m & \text { Mass flow rate } \\ P & \text { Pressure } \\ P r & \text { Pressure ratio } \\ P W & \text { Power } \\ Q & \text { Vector of flow variables } \\ R & \text { Radius }\end{array}$

$\begin{array}{ll}R 2 & \text { Riemann invariant } \\ T & \text { Temperature } \\ u, v, w & \text { x, y, z components of velocity } \\ x, y, z & \text { Cartesean coordinates } \\ y^{+} & \text {Boundary Layer Parameter } \\ \alpha & \text { Circumferential flow angle, absolute } \\ \beta & \text { Circumferential flow angel, relative } \\ \Delta h & \text { Work per unit of fluid } \\ \gamma & \text { Ratio of Specific Heats } \\ \mathrm{b} & \text { Yaw angle, absolute } \\ \psi & \text { Yaw angle, relative }\end{array}$

\begin{tabular}{cl} 
Subscripts & \\
\cline { 1 - 2 }$N E$ & Nozzle exit \\
$T$ & Total (stagnation) quantity \\
$t$ & time \\
$t-s$ & Total to static quantity \\
0 & Nozzle inlet \\
$l$ & Rotor inlet \\
2 & Rotor exit
\end{tabular}

\section{INTRODUCTION}

Flowfield unsteadiness is a major factor in turbine performance and durability. This is particularly true if the turbine is a high work design, compact, transonic, supersonic, counter rotating, or uses a dense drive gas. Most modern rocket engine turbines fall within these categories. For example, the Space Transportation Main Engine (STME) fuel turbine, a high work, transonic design, was predicted to have an unsteady inter-row shock that reduced efficiency by two points and increased dynamic loading by 24 percent (Rangwalla, et al., 1992). The Revolutionary Reusable Technology Turbopump (RRTT) turbine, which uses full flow oxygen as its drive gas, was predicted to shed vortices with such energy as to raise serious concerns about the blade's durability (Griffin and Nesman, 1996). In both cases, the sources of the problems were uncovered before turbopump 
testing with the application of validated, unsteady CFD to the designs.

As requirements for smaller and lighter weight components push turbines to more compact, closely coupled designs, flow unsteadiness increases. Current designs such as the Fastrac turbine and future designs like the RLV fuel turbine add the complexities of supersonic flow regimes. The ability to accurately predict this flow unsteadiness in a timely manner is crucial to producing a design that meets program objectives.

In this study, the unsteady aerodynamic environment of the Fastrac turbine has been analyzed. The objective of the Fastrac Engine project is to demonstrate a reliable, low cost turbopump-fed rocket engine. The development strategies included simple engine system design, a simple approach to turbomachinery design, reduced number of parts, the use of commercial manufacturing techniques, and the use of commercial off the shelf components. The engine uses a gas generator cycle and is fueled by a mixture of liquid oxygen and kerosene. Pumps are used to increase the pressure of the propellants. These pumps, one for each propellant, are on a single shaft and are powered by one turbine. A drawing of the cross section of the turbopump is shown in Fig. 1. Modal analysis of the turbine blade indicates possible resonance near a crucial operating speed, as shown in the Campbell diagram (Fig. 2). The diagram shows crossovers of excitations at blade bending modes due to twice the nozzle count, and due to the EGVs within a $10 \%$ margin of the nominal design speed. Unsteady CFD analysis was used to support the aerodynamic assessments of blade loading and efficiency, and the structural dynamic evaluations by providing unsteady pressures for transient response analysis. The results of the CFD analysis are presented.

To aid in the understanding of the effects of the axial spacing between the nozzle and blade on the flow unsteadiness, calculations were performed for the Fastrac turbine for two different axial spacings. The intent of the

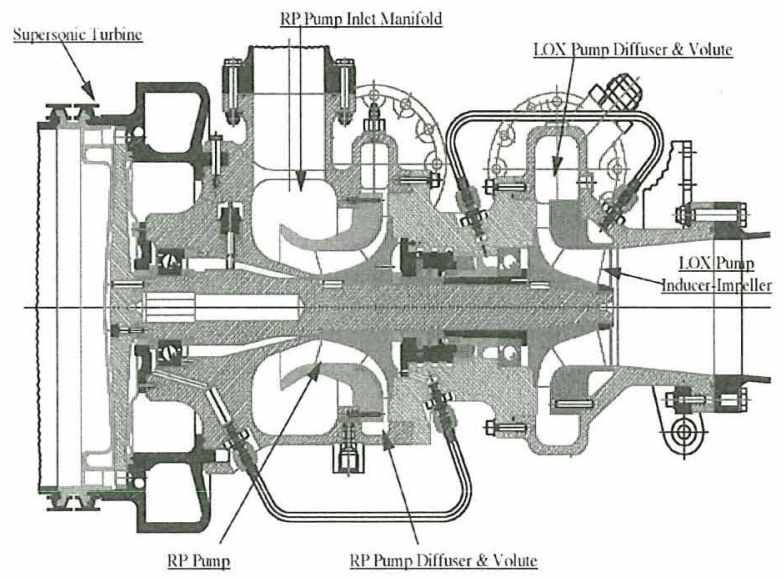

FIG. 1: CROSS SECTION OF THE FASTRAC TURBOPUMP analysis was to study the effects of the axial spacing on both flow unsteadiness and on the efficiency of supersonic turbines. This information will benefit future designs, such as for RLV, where turbine performance is a premium. In addition, calculations were performed for the nozzle alone, and the results were imposed as an inlet boundary condition for a blade/EGV calculation for the large axial gap case. These results are compared to the nozzle/blade/EGV results. This calculation was performed to determine the necessity of coupling the nozzle to the rest of the turbine for the unsteady analysis of supersonic turbines.

Before beginning the analysis of the coupled nozzle/blade/EGV calculation, two major difficulties with the unsteady analysis software used in this study had to be addressed: modeling a straight centerline nozzle with the turbine blades and exit guide vanes (EGVs), and reducing run times significantly while maintaining physical accuracy. Implementing Message Passing Interface (MPI) software into the numerical analysis was the method chosen to enable these calculations with the required speed.

\section{TURBINE DESCRIPTION}

The Fastrac turbine is a single stage, full admission supersonic design with exit guide vanes. The turbine is required to produce $895 \mathrm{~kW}$ and spins at 20,000 RPM. The nozzle ring contains 24 converging-diverging, straight centerline nozzles with circular cross sections and throat diameters of $0.615 \mathrm{~cm}$. There are 147 impulse-type, shrouded blades with heights of $1.045 \mathrm{~cm}$, which is $20 \%$ larger than the minor axis of the nozzle exit ellipse. They have a mean diameter of $24.46 \mathrm{~cm}$ and an axial chord of $0.838 \mathrm{~cm}$ The blades are a two-dimensional (2D) design with identical airfoil sections from hub to tip. There are $67 \mathrm{EGVs}$ with heights of $1.045 \mathrm{~cm}$, mean diameter of $24.46 \mathrm{~cm}$, and axial chords of $1.524 \mathrm{~cm}$. The EGVs are also a 2D design. Axial spacing between the nozzles and blades is $0.102 \mathrm{~cm}$ and between blades and EGVs is $1.02 \mathrm{~cm}$.

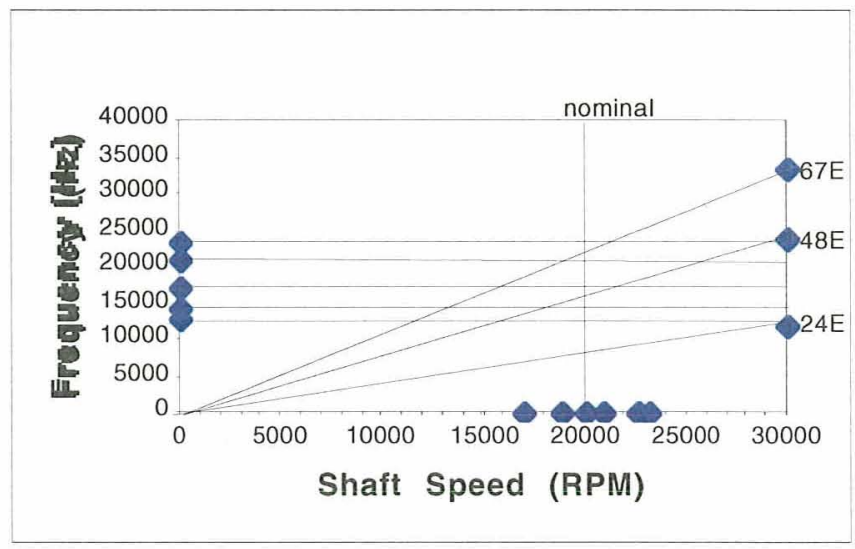

FIG. 2. FASTRAC TURBINE BLADE CAMPBELL DIAGRAM W/ MOST RESPONSIVE MODES AND EXCITATIONS 
The turbine is driven by a mixture of gaseous kerosene and oxygen with a ratio of specific heats, $\gamma$, of 1.108 and a specific heat at constant pressure, $\mathrm{c}_{\mathrm{p}}$, of $2.64 \mathrm{~kJ} / \mathrm{kg}{ }^{\circ} \mathrm{K}$. The gas enters the nozzles with a total pressure, $P_{T o}$, of $3.79 \mathrm{MPa}$ a total temperature, $T_{T o}$, of $889^{\circ} \mathrm{K}$, and a mass flow rate of 3.24 $\mathrm{kg} / \mathrm{sec}$. Meanline calculations predict the Mach number at the exit of the nozzle to be 2.11 . The total to static pressure ratio, $P r_{t-s,}$ across the nozzle was designed to be 11.2.

\section{METHOD OF SOLUTION}

The flowfield of the Fastrac turbine was numerically analyzed using a parallelized, unsteady, three-dimensional (3D) Navier-Stokes code. The methodology, approach, and grid system are discussed in the following sections.

\section{Numerical Algorithm}

The governing equations considered in this study are the time-dependent, 3D, Reynolds-averaged Navier-Stokes equations:

$$
Q_{t}+\left(F_{i}+F_{v}\right) x+\left(G_{i}+G_{v}\right)_{y}+\left(H_{i}+H_{y}\right)_{z}=0
$$

The viscous fluxes are simplified by incorporating the thin layer assumption (Baldwin, 1978). In the current study, viscous terms are retained in the direction normal to the hub and shroud surfaces. To extend the equations of motion to turbulent flows, an eddy viscosity formulation is used. The turbulent viscosity, $\mu_{T}$, is calculated using the two-layer Baldwin-Lomax (1978) algebraic turbulence model.

The numerical algorithm used in the 3D computational procedure consists of a time-marching, implicit, finitedifference scheme. The procedure is third-order spatially accurate and second order temporally accurate. The inviscid fluxes are discretized according to the scheme developed by Roe (1981). The viscous fluxes are calculated using standard central differences. An alternating direction, approximatefactorization technique is used to compute the time rate of change in the primary variables. Newton sub-iterations are used at each global time step to increase stability and to reduce linearization errors. For all cases investigated in this study, two Newton sub-iterations were performed at each time step. Further information on the numerical procedure can be found in Dorney et al. (1992, 1998).

The CFD code used for this study has been widely validated for flows in turbomachinery. Examples of validation cases are given in Dorney and Sondak (1996), Dorney and Schwab (1996). Dorney and Davis (1992, 1993), and Dorney, et al. (1992).

\section{Boundary Conditions}

The theory of characteristics is used to determine the boundary conditions at the inlet and exit of the computational domain. For subsonic inlet flow, four quantities are specified, and one is extrapolated from the interior of the computational domain. In particular, the total pressure, total temperature, and the $v$ and $w$ components of velocity are specified as a function of the radius. The upstream running Riemann invariant, $R_{2}=u-\frac{2 a}{\gamma-1}$, is extrapolated from the interior of the computational domain.
For subsonic outflow, one flow quantity is specified and four are extrapolated from the interior of the computational domain. The $v$ and $w$ velocity components, entropy, and the downstream running Riemann invariant are extrapolated from the interior of the computational domain. The pressure ratio, $P_{R t-s}$ is specified at the midspan of the computational exit, and the pressures at all other radial locations at the exit are obtained by integrating the equation for radial equilibrium. For supersonic outflow, all of the flow variables are extrapolated. Periodicity is enforced along the outer boundaries of the H-grids in the circumferential direction.

For viscous simulations, no-slip boundary conditions are enforced along the solid surfaces. Absolute no-slip boundary conditions are enforced along the walls of the nozzle, at the hub and tip end walls of the vane passages, and along the surface of the vanes. Relative no-slip boundary conditions are imposed at the hub, shroud, and surfaces of the blades. It is assumed that the normal derivative of the pressure is zero at solid wall surfaces. In addition, a specified (zero) heat flux distribution is held constant in time along the solid surfaces.

The flow variables of $Q$ at zonal boundaries are explicitly updated after each time step by interpolating values from the adjacent grids.

\section{Code Parallelization}

The MPI software has been implemented into the numerical analysis. Implementing this software allows the following two advantages: 1) the simulation of a single problem can be run on multiple processors to dramatically reduce run times, and 2) the simulation of multiple problems (each of which can be performed on multiple processors) can be linked through the passing of boundary condition information. In this study, one nozzle from the nozzle ring has been linked with the simulation of a supersonic turbine containing six rotors and three EGVs.

\section{Grid System}

The Fastrac turbine has a nozzle-to-blade-to-EGV ratio of $24: 147: 67$. For the current study, the ratio was modeled as 1:6:3. The blades were scaled by a ratio of $147 / 150$ and the EGVs by a ratio of $67 / 75$ to keep the pitch to chord ratio constant.

The grid for the nozzle was an H-type grid. The solid walls at the exit plane of the nozzle ring were modeled. The rotor inlet grid is an $\mathrm{H}$-grid. The grid around each airfoil consists of an inner and outer zone. The inner zone is discretized with an $\mathrm{O}$ grid surrounding the airfoil. The $\mathrm{O}$-grids are overlaid onto $\mathrm{H}$-grids which discretize the outer zones. The H-grids are patched between blade rows and the rotor $\mathrm{H}$-grids slide past the nozzle H-grid and the EGV $\mathrm{H}$-grids in time. The average value of $y$ was approximately 1.0 for the airfoil surfaces and 4.0 for the endwall surfaces. Figure 3 shows the grid. Every third point in the grid was plotted, and only a portion of the outflow section of the EGV grid is shown. Grid densities are shown in Table 1. The total number of grid points for each calculation was $1,545,987$. The grid densities were chosen based on a compromise between accuracy needed for a design calculation and computational time. Previous simulations suggested that 41 radial planes is adequate. 


\begin{tabular}{|c|c|c|c|c|}
\hline Grid Type & Nozzle & $\begin{array}{c}\text { Rotor Inlet } \\
\text { Grid }\end{array}$ & Rotor $(\times 6)$ & EGV $(\times 3)$ \\
\hline$O$ & NA & NA & $91 \times 21 \times 41$ & $91 \times 21 \times 41$ \\
\hline H & $108 \times 38 \times 41$ & $14 \times 51 \times 41$ & $64 \times 21 \times 41$ & $82 \times 31 \times 41$ \\
\hline Total & 168,264 & 29,274 & 800,730 & 547,719 \\
\hline
\end{tabular}

TABLE 1: GRID DIMENSIONS (PER PASSAGE) FOR THE SMALL GAP AND LARGE GAP

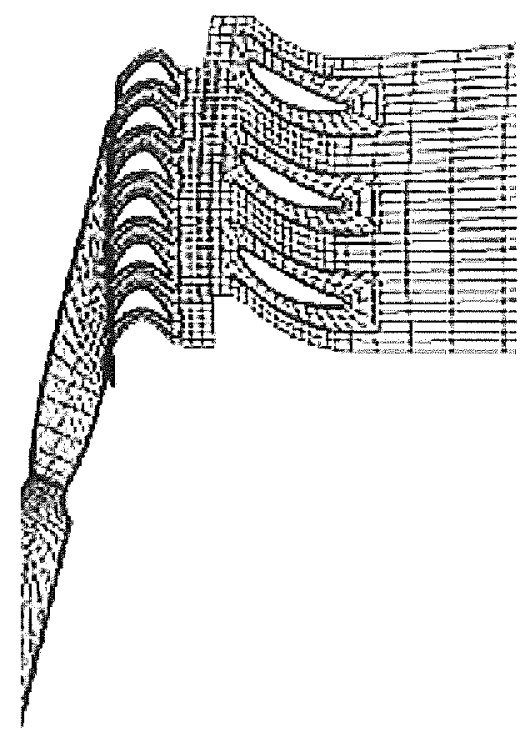

FIG. 3. TURBINE GRID (EVERY $3^{\text {RD }}$ POINT PLOTTED)

\section{RESULTS AND DISCUSSION}

Results of the unsteady simulations of the Fastrac turbine are presented for the design case (small gap), large axial gap case, and uncoupled case. Results from each case are compared.

\section{Design Case (Small Gap)}

Predicted flow conditions at the inlet and the exit of the rotor for a nozzle to rotor axial gap of $0.102 \mathrm{~cm}$ are given in Table 2. This axial spacing is equal to the actual axial gap in the Fastrac turbine. Work per pound of gas is calculated using Eqn. 2.

$$
\Delta h=c_{p}\left(T_{r)}-T_{r 2}\right)
$$

Using the predicted flow conditions, the work per pound of flow is calculated to be $276.3 \mathrm{kj} / \mathrm{kg}$. Power is defined as

$$
P W=m \times \Delta h
$$

and is ealculated to be $890 \mathrm{~kW}$.

Predicted instantaneous Mach number contours at midspan are shown in Fig. 4. Subsonic flow enters the nozzle, chokes at the throat, and becomes supersonic. A Mach disk is seen downstream of the throat. Shock waves form in the diverging section and reflect off the nozzle walls. The fluid expands as it leaves the nozzle. Supersonic flow enters the blade, and a leading edge shock is formed. The

\begin{tabular}{|c|c|c|}
\hline Variable & Absolute & Relative \\
\hline$M_{I}$ & 2.01 & 1.21 \\
\hline$M_{2}$ & 0.44 & 0.82 \\
\hline$T_{T I}$ & $889^{\circ} \mathrm{K}$ & $804^{\circ} \mathrm{K}$ \\
\hline$T_{T 2}$ & $780^{\circ} \mathrm{K}$ & $800^{\circ} \mathrm{K}$ \\
\hline$P_{T /} / P_{0}$ & 0.933 & 0.269 \\
\hline$P_{T 2} / P_{0}$ & 0.143 & 0.186 \\
\hline$\alpha_{1}$ and $\beta_{I}$ & $70.4^{\circ}$ & $51.0^{\circ}$ \\
\hline$\alpha_{2}$ and $\beta_{2}$ & $-7.7^{\circ}$ & $-58.9^{\circ}$ \\
\hline$\psi_{1}$ and $\phi_{1}$ & $-0.9^{\circ}$ & $-0.1^{\circ}$ \\
\hline$\psi_{2}$ and $\phi_{2}$ & $0.0^{\circ}$ & $0.0^{\circ}$ \\
\hline
\end{tabular}

TABLE 2. PREDICTED ROTOR CONDITIONS, SMALL GAP

boundary layer separates from the suction surface of the blade due to interaction with the shock. The size of the separation is dependent upon the blade's circumferential position relative to the nozzle. Because of the large separated region on the blade, the average Mach number at the exit of the blade is subsonic. The boundary layer near the trailing edge of the EGV separates. Separation on the pressure surface of the EGV is dependent on the circumferential position of the blades.

To determine the mechanism of the increased separation on the blade and the separation on the pressure side of the EGV, instantaneous entropy contours were plotted (Fig. 5). The contours show a wake produced at the lip of each nozzle. This wake is due to the solid wall regions between each nozzle at the exit plane of the nozzle ring. The wake triggers an earlier separation on the suction surface of the blades than when the blade is fully within the nozzle jet. When this boundary layer sheds, this higher loss flow travels downstream causing the separation on the pressure side of the EGV.

Pressure envelopes for the blade are shown in Figs. 6a-c. Large amounts of unsteadiness are predicted, particularly at the blade leading edge. Less unsteadiness is exhibited in the hub and shroud regions than at midspan. Because the blade is $20 \%$ taller than the minor axis of the ellipse of the nozzle exit, the jet from the nozzle has not expanded enough to impact these regions near the leading edge of the blade for this small nozzle/blade axial spacing.

A Fourier decomposition was performed for the predicted unsteady environment. Figures $7 \mathrm{a}-\mathrm{b}$ show the half amplitudes at discrete frequencies for the blade. The nozzle passing frequency is $8000 \mathrm{hz}$., and the second harmonic of nozzle passing is at $16000 \mathrm{hz}$. Large amounts of unsteadiness exist at the leading edge for these frequencies. The unsteadiness at the nozzle passing frequency persists as the flow travels over the pressure surface. The pressure fluctuations at the nozzle passing frequency decrease rapidly on the suction surface with distance from the leading edge. However, even after separation, the second harmonic of nozzle passing persists, albeit to a lesser extent than at the leading edge. 


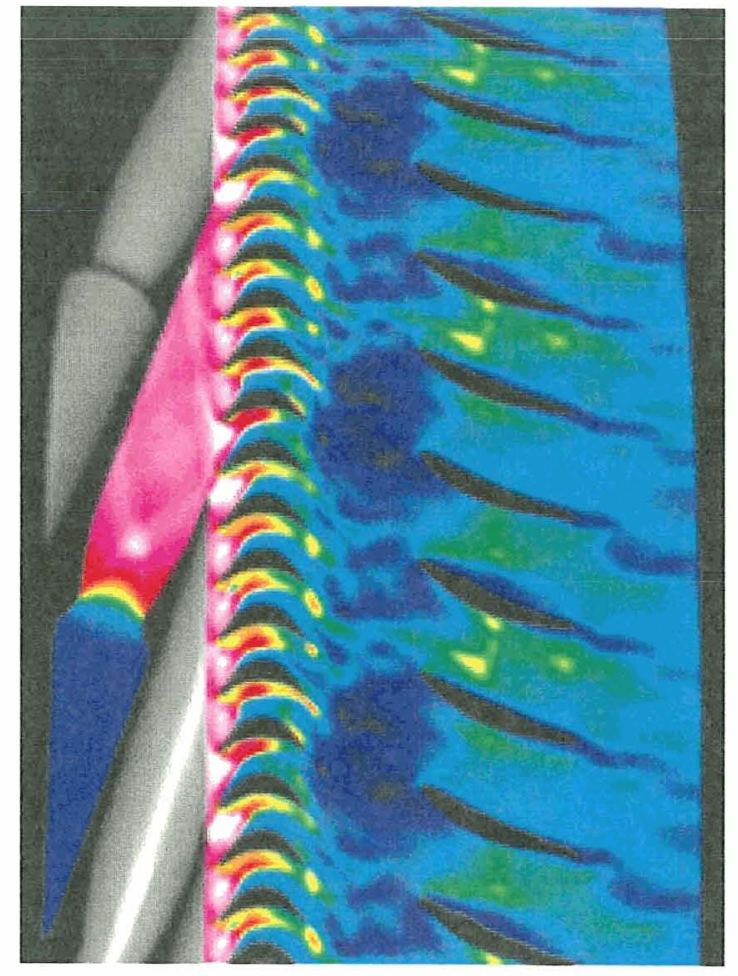

FIG. 4. INSTANTANEOUS MACH CONTOURS

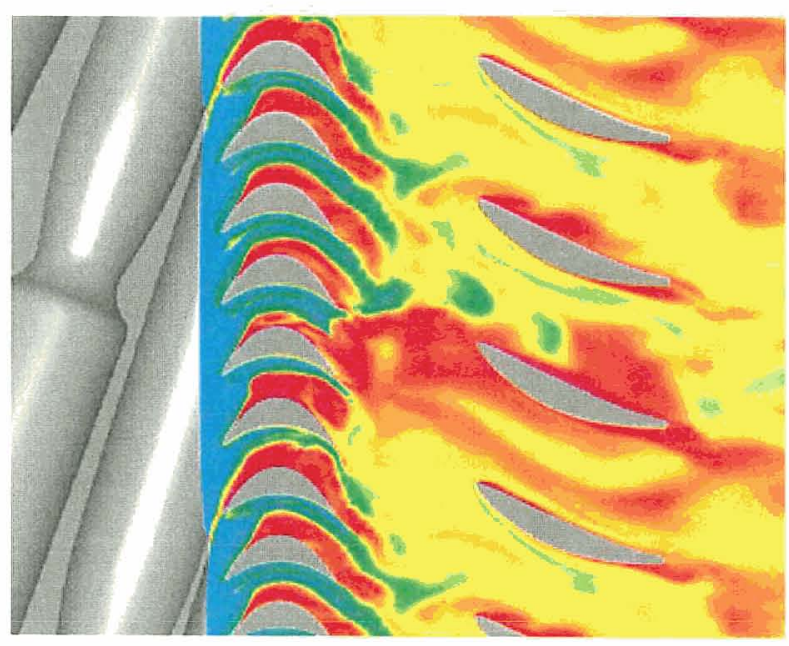

FIG. 5. INSTANTANEOUS ENTROPY CONTOURS

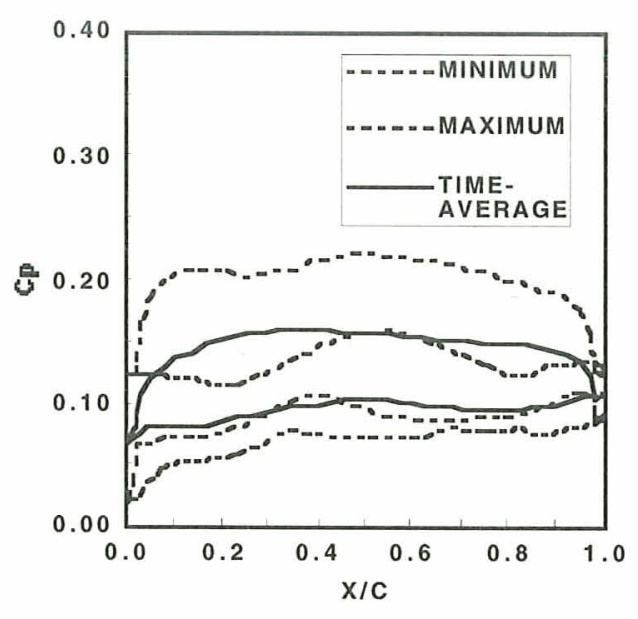

(a) Hub

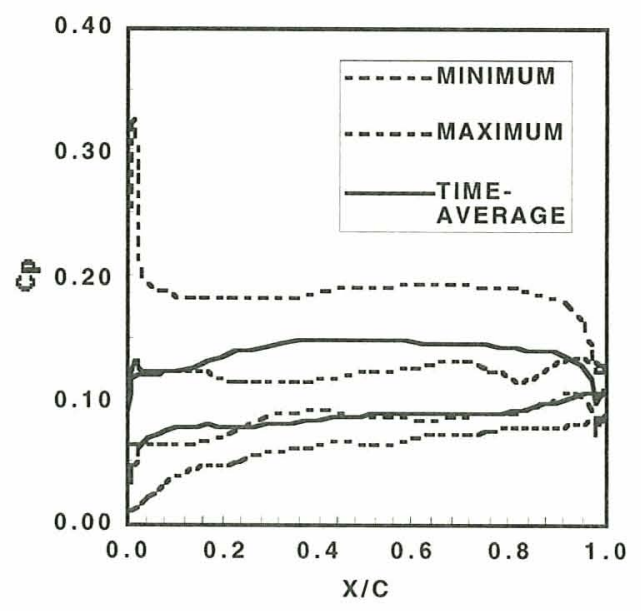

(b) MIDSPAN

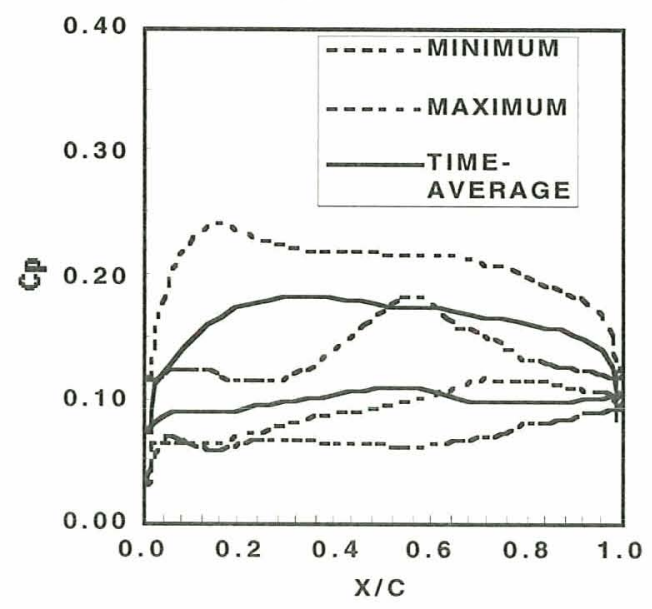

(c) TIP

FIG. 6. ROTOR PRESSURE ENVELOPES, SMALL GAP 


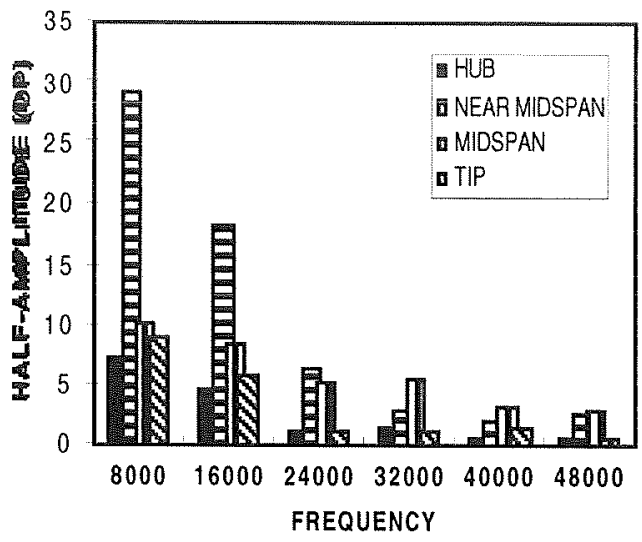

(a) LEADING EDGE

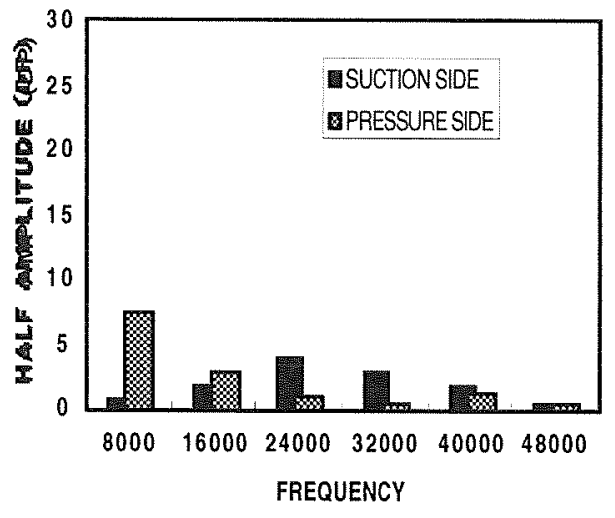

(b) $20 \%$ AXIAL CHORD

FIG. 7. FOURIER DECOMPOSITION OF PRESSURES FOR BLADE

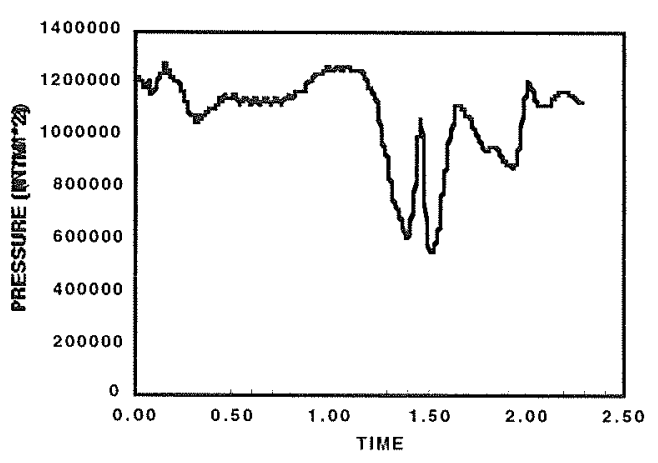

FIG. 8. PRESSURE TRACE FOR BLADE LEADING EDGE, MIDSPAN
A pressure trace at the rotor leading edge at midspan is shown in Fig. 8. The time period for the trace is for one blade to pass one nozzle. The pressure deficit clearly shows the presence of the solid wall regions at the nozzle exit plane.

\section{Large Gap Case}

Because the unsteadiness is large at the leading edge of the blade for the design case, a larger axial spacing was considered. The spacing for this large gap case was set at $0.838 \mathrm{~cm}$, or one blade axial chord. Predicted flow conditions at the inlet and the exit of the rotor are given in Table 3. Work per pound of gas is calculated to be $269.1 \mathrm{~kJ} / \mathrm{kg}$, and the power output is $867 \mathrm{~kW}$. These values are lower than those predicted for the small gap case. The non-dimensional total pressure, $\left(\mathrm{P}_{\mathrm{T}} / \mathrm{P}_{0}\right)$, is lower at the inlet to the blade for the large gap case than for the small gap case. The nondimensional total pressures at the exit of the nozzle are comparable for both cases $\left(\mathrm{P}_{\mathrm{TNE}} / \mathrm{P}_{0}=1.001\right.$ for the large gap case and 1.005 for the small gap). The increase in total pressure loss ahead of the blade for the large gap case is in the axial gap region. With the increased axial gap, the jet from the nozzle is allowed to more fully expand before reaching the blade. The additional expansion allows for interaction between the jets of successive nozzles. This interaction of supersonic flows creates additional loss.

\begin{tabular}{|c|c|c|}
\hline Variable & Absolute & Relative \\
\hline$M_{1}$ & 1.97 & 1.29 \\
\hline$M_{2}$ & 0.41 & 0.74 \\
\hline$T_{T I}$ & $889^{\circ} \mathrm{K}$ & $802^{\circ} \mathrm{K}$ \\
\hline$T_{l 2}$ & $782^{\circ} \mathrm{K}$ & $800^{\circ} \mathrm{K}$ \\
\hline$P_{T /} / P_{0}$ & 0.806 & 0.271 \\
\hline$P_{T 2} / P_{0}$ & 0.146 & 0.180 \\
\hline$\alpha_{1}$ and $\beta_{I}$ & $74.2^{\circ}$ & $58.1^{\circ}$ \\
\hline$\alpha_{2}$ and $\beta_{2}$ & $1.6^{\circ}$ & $-58.9^{\circ}$ \\
\hline$\psi_{1}$ and $\phi_{1}$ & $2.8^{\circ}$ & $-8.2^{\circ}$ \\
\hline$\psi_{2 \text { and }} \phi_{2}$ & $-0.4^{\circ}$ & $2.6^{\circ}$ \\
\hline
\end{tabular}

TABLE 3. PREDICTED ROTOR CONDITIONS, LARGE GAP

Pressure envelopes are shown in Figs. 9a-c. A large amount of unsteadiness is evident on the blade, especially at the leading edge, as was also shown for the small gap case. However, the unsteadiness at the shroud is greater in the large gap case than for the small gap because the jet from the nozzle has had sufficient space to expand into the tip region.

A Fourier decomposition of the unsteady data was performed. Plots are shown in Figs. 10a-b. As the gap was increased, the fluctuating pressures at the blade leading edge at nozzle passing frequency have decreased. However, large pressure fluctuations at the second harmonic of the nozzle passing frequency are exhibited for the large gap case. Unsteadiness due to nozzle passing persists as the flow travels over the pressure side of the blade. The second harmonic is also prominent, as in the small gap case. Unlike the small gap case, however, an increase in fluctuating pressures at nozzle passing frequency was predicted with 


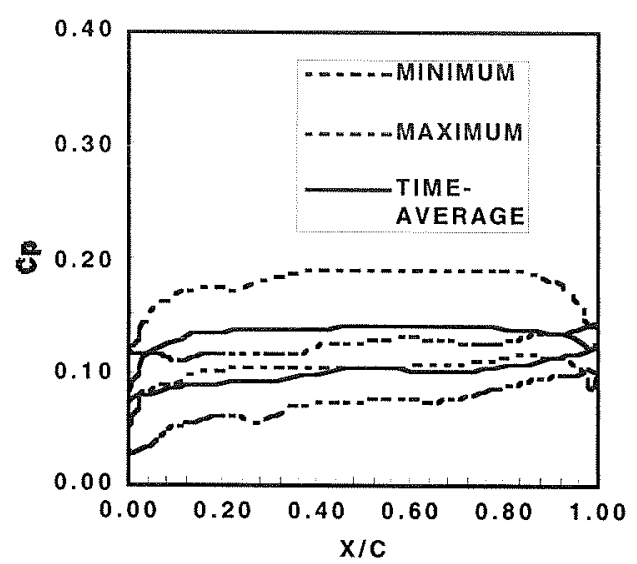

(a) HUB

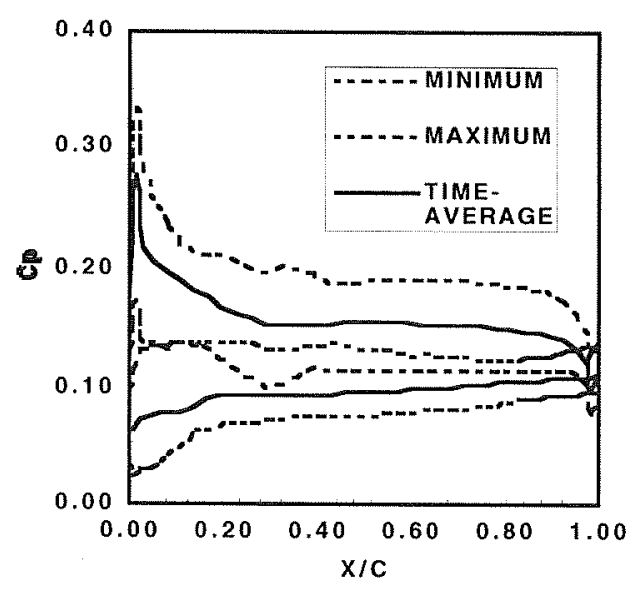

(b) MIDSPAN

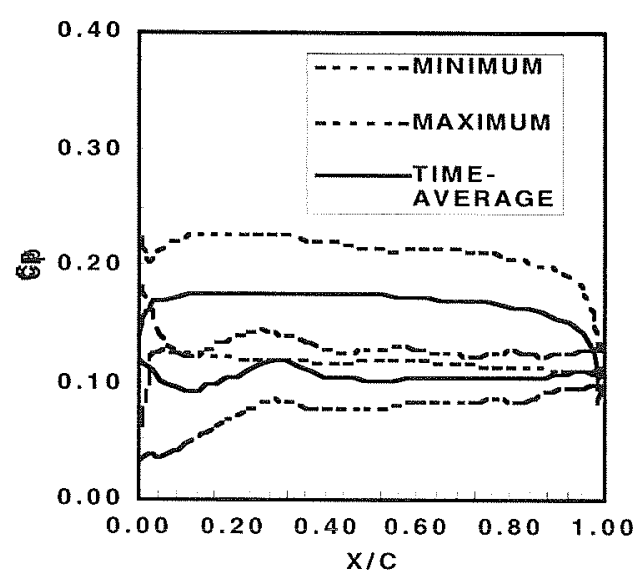

(c) TIP

FIG.9. BLADE PRESSURE ENVLEOPES, LARGE GAP

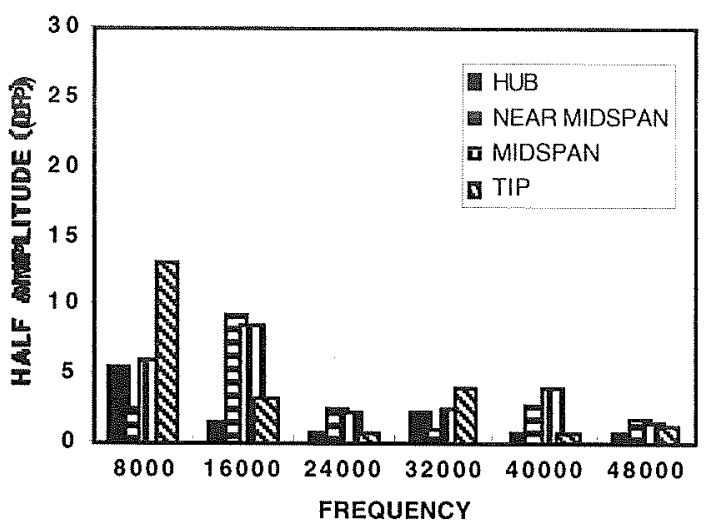

(a) LEADING EDGE

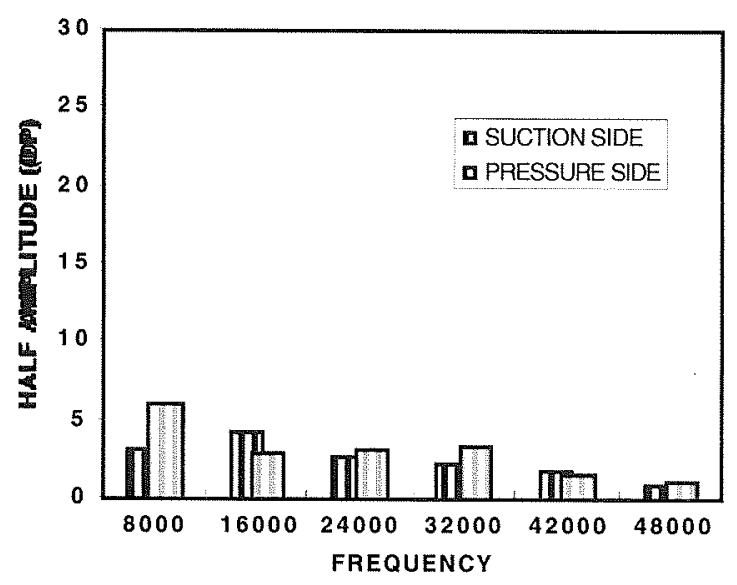

(b) $20 \%$ AXIAL CHORD

FIG. 10. FOURIER DECOMPOSITION OF PRESSURES FOR BLADE, LARGE GAP

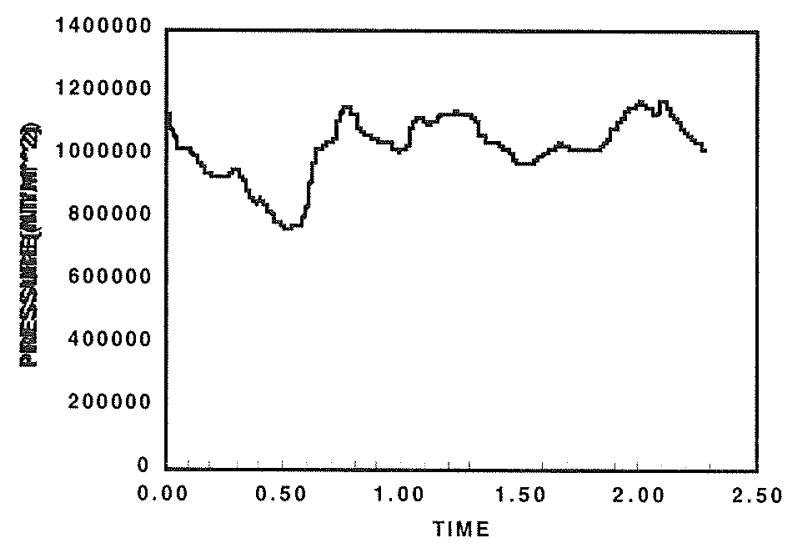

FIG. 11. PRESSURE TRACE FOR BLADE LEADING EDGE, MIDSPAN, LARGE GAP 
increasing distance along the suction surface until flow separation. This is believed to be due to the additional expansion of the nozzle jet.

A pressure trace at the leading edge of the blade at midspan is shown in Fig. 11. Although the nozzle wake is still evident, the deficit in pressure is smaller for the large gap case. The second harmonic of the nozzle passing frequency can also be seen in this plot.

\section{Uncoupled Nozzle and Blade/EGV Case}

A simpler calculation than coupling the nozzle to the blades and EGVs is to simulate the nozzle flowfield and impose the results from the exit of the nozzle as an inlet boundary condition for a blade/EGV simulation. This procedure poses a numerical problem due to the difficulties in applying a unique incidence boundary condition for the blade. Setting the inlet boundary at the exit of the nozzle will not allow pressure waves to move upstream; therefore, shocks can reflect back into the flow domain. Moving the boundary further upstream would mitigate this problem, but the nozzle jet would not be properly modeled. However, because of the reduced computer resource requirements, modeling the supersonic turbine in this manner is tempting. This procedure was conducted for the large axial gap. The elliptical nozzle exit was roughly modeled at the inlet of the blade/EGV domain. Work per pound of fluid was calculated to be $244 \mathrm{~kJ} / \mathrm{kg}$, and the power produced was $787 \mathrm{~kW}$. These numbers are significantly different from the coupled cases.

Pressure envelopes are shown in Figs. 12a-c. The pressure envelopes look somewhat similar to those from the large gap coupled simulation, which is not surprising. As the gap between the nozzle and blade increases, the coupled and uncoupled solutions should look increasingly similar. Note, however, that even though the unsteady envelopes (which constitute the sum of all the unsteady frequencies) are similar, the amplitudes of the unsteadiness at discrete frequencies are different in the coupled and uncoupled cases.

\section{Comparisons of Radial Profiles}

To further illustrate the differences between cases and to improve the understanding of these differences, time-averaged radial profiles of flow variables at the inlet and exit of the blade were plotted for each case. Figures 13a-b show circumferential flow angles. At this station, the nozzle jet for the large gap case has had time to expand. The jet has not expanded as fully for the small gap case, and the boundary layers at the hub and tip are larger. The flow angles for the uncoupled case are similar to the coupled large gap case except at the endwalls. The jump in flow angle near the endwalls is indicative of an improper prediction of mixing at the nozzle exit (or right at the inlet of the flow domain for the uncoupled case). At the blade exit, the small gap and large gap cases have similar angle profile shapes. However, the exit flow angles for the small gap case are more negative (which is more beneficial). The difference in the magnitudes of the exit flow angles seems to be due to greater airfoil separation for the large gap case, and the differing inlet boundary layer profiles. For the uncoupled case, the flow angles are more negative indicating an under prediction of airfoil separation. The profile shape is dissimilar to those of

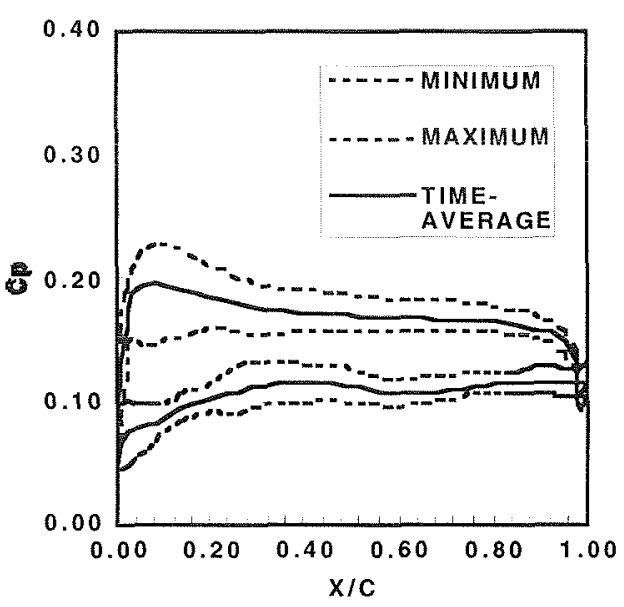

(a) HUB

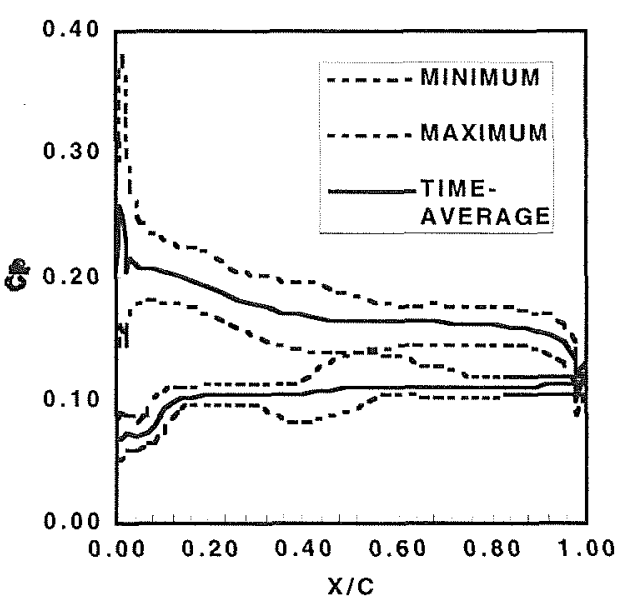

(b) MIDSPAN

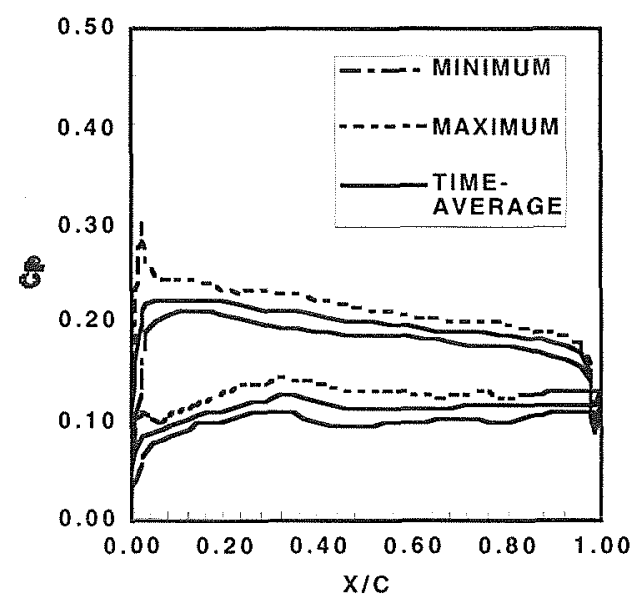

(c) TIP

FIG. 12. BLADE PRESSURE ENVELOPES, LARGE GAP, UNCOUPLED 


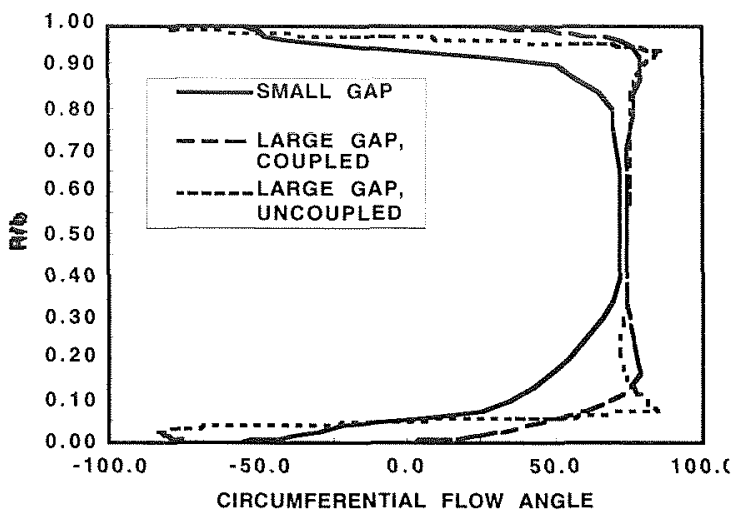

(a) BLADE INLET

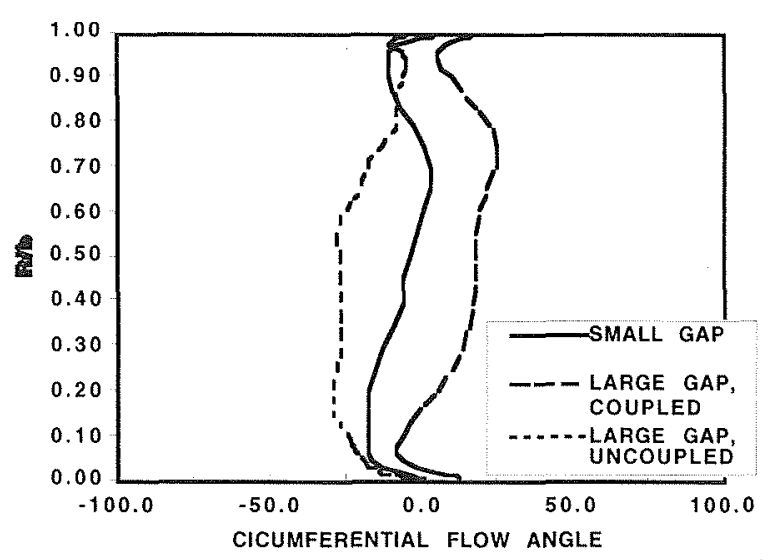

(b) BLADE EXIT

FIG. 13. CIRCUMFERENTIAL ANGLE PROFILES

either of the coupled cases. The difference is not surprising considering the shape of the inlet boundary layer profile.

Figures $14 \mathrm{a}-\mathrm{b}$ shows total pressure, $P_{T}$, at the inlet and exit of the blade. There are regions of higher loss entering the blade for the small gap case than for the large gap case. Because the nozzle jet has not yet expanded into the blade endwall regions, the boundary layers at the inlet section are thick for the small gap case. The profile for this case is nearly symmetric about the midspan. However, the profile shape for the large gap case is not symmetric. The nozzle jet expands into the blade shroud region before entering the hub region, thereby thinning the boundary layer at the shroud. The uncoupled case produces a profile that is nearly uniform with thin boundary layers. The losses for this case are under predicted. Differences persist at the exit of the blade. For the small gap case, there is a dip in total pressure from both endwalls to midspan. The total pressure at the exit station for the large gap is nearly uniform outside of the boundary layers. The uncoupled case again shows very thin boundary layers.

\section{CONCLUSIONS}

A numerical study of the unsteady aerodynamic environment of the Fastrac supersonic turbine was conducted. The results were used to support aerodynamic assessments and structural dynamics evaluations. The design

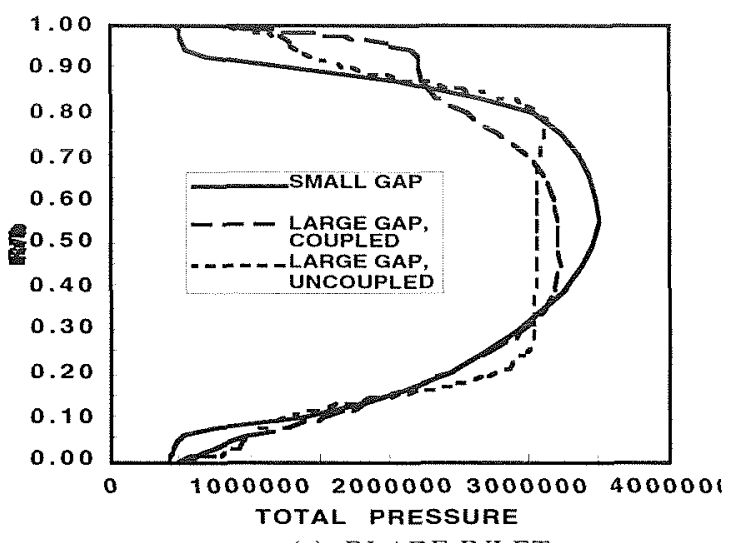

(a) BLADE INLET

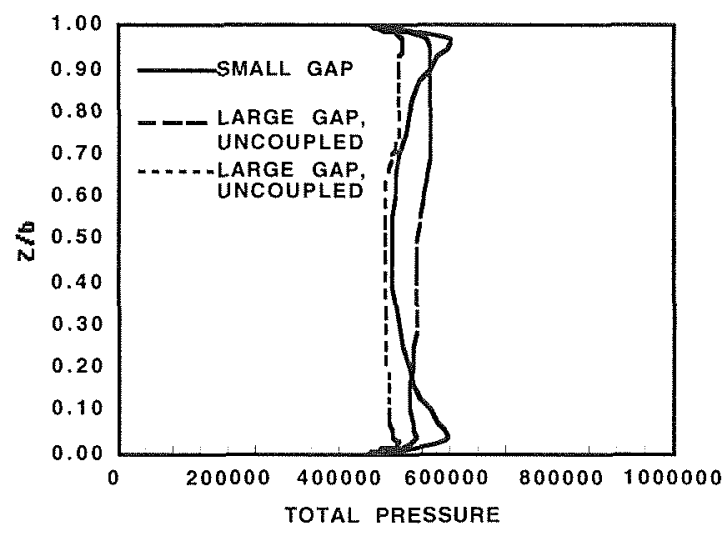

(c) BLADE EXIT

FIG. 14. TOTAL PRESSURE PROFILES

case (small gap) calculation showed that the turbine produces the required power. It also shows highly loaded blades, but no severe loading or unloading. However, the calculation also shows a high degree of unsteadiness, a nozzle with reflecting shocks, and a blade with large separation on the suction side. Relatively high amplitude pressure unsteadiness is predicted at the nozzle passing frequency and its second harmonic, particularly at the blade leading edge. The fluctuating pressures of these harmonics are evident along the pressure surface of the blade and the suction surface of the blade until the boundary layer separates. Thick boundary layers are evident at the inlet of the blade due to the nozzle jet not yet expanding into the endwall regions of the taller blade. The wake produced by the solid wall regions between nozzles interacts with the blade flowfield causing earlier separation, and separation on the pressure side of the EGV.

In order to investigate the effects of nozzle to blade axial spacing, a second case with a larger axial gap was simulated. This case showed higher losses in the region between the nozzle and blade due to jet interaction. However, it also showed less blade unsteadiness and thinner boundary layers entering the blade. Power calculated for the large gap case was lower than for the small gap case. However, this fact in no way implies that the smallest spacing is always optimal. More simulations of different axial spacings must be 
conducted, and the flowfield in the axial gap region must be studied in detail. The authors plan to perform this study in the future.

An uncoupled nozzle and blade/egv simulation was run to determine if the more complicated coupled simulations were necessary. This case showed that the inlet conditions were over-specified, the mixing in the axial gap was not adequately simulated, and the losses were under predicted. It is the opinion of the authors that the nozzle must be coupled to the blade for unsteady simulations of supersonic turbines.

\section{ACKNOWLEDGMENTS}

The authors wish to acknowledge the important contributions made to this work by our colleagues. Thomas Zoladz provided expertise in understanding unsteady flow phenomena. His support was most appreciated. The authors also wish to thank the Advanced Space Transportation Program at NASA/MSFC for their support of this acitivity.

\section{REFERENCES}

Baldwin, B. S., and Lomax, H., 1978, "Thin Layer Approximation and Algebraic Model for Separated Turbulent Flow," AIAA Paper 78-257, Huntsville, AL, January,

Dorney, D. J., Davis, R. L., Edwards, D. E., and Madavan, N. K., 1992, "Unsteady Analysis of Hot Streak Migration in a Turbine Stage," Journal of Propulsion and Power, Vol. 8, No. 2, March-April, pp. 520-529.

Dorney, D. J., and Davis, R. L., 1992, "Navier-Stokes Analysis of Turbine Blade Heat Transfer and Performance," ASME Journal of Turbomachinery, Vol. 114, No. 4, October, pp. 795-806.

Dorney, D. J., and Davis, R. L., 1993, "Numerical Simulation of Turbine "Hot Spot" Alleviation Using Film Cooling," AIAA Journal of Propulsion and Power, Vol. 9, No.3, May-June, pp. 329-336.

Dorney, D. J., and Sondak, D. L., 1996, "Study of Hot Streak Phenomena in Subsonic and Transonic Flow," International Journal of Turbo and Jet Engines, Vol. 13, No. 2, pp. 131-141.

Dorney, D. J., and Schwab, J. R., 1996, "Unsteady Numerical Simulations of Radial Temperature Profile Redistribution in a Single-Stage Turbine," ASME Journal of Turbomachinery, Vol. 118, No. 4, October, pp. 783-791.

Dorney, D. J., 1998, "Rapid Prediction of Unsteady Three-Dimensional Viscous Flows in Turbopump Geometries," NASA

H-28721D Final Report, March 21.

Griffin, L. W., and Rowey, R. J., 1993, "Analytical Investigation of the Unsteady Aerodynamic Environments in Space Shuttle Main Engine (SSME) Turbines", ASME Paper No. 93-GT-363, Cincinnati, OH, June.
Griffin, L. W., and Huber, F. W., 1993, "Advancement of Turbine Aerodynamic Design Techniques", ASME Paper No. 93-GT-370, Cincinnati, OH, June.

Garcia, R., Griffin, L. W., Benjamin, T. G., Cornelison, J. W., Ruf, J. H., and Williams, R. W., 1995, "Computational Fluid Dynamics Analysis in Support of the Simplex Turbopump Design", NASA CP-3282 Vol. 1, pp. 462-470.

Griffin, L. W., Huber, F. W., and Sharma, O. P., 1996, "Performance Improvement Through Indexing of Turbine Airfoils: Part 2: Numerical Simulation", (lem ASME Journal of Turbomachinery, Vol. 118, No. 4, pp. 636-642.

Griffin, L. $\sim$ W., and Nesman, T., 1996, "Prediction of the Unsteady Aerodymanic Environment in the RRTT Turbine", presented at the 14th Workshop for Fluid Dynamic Applications in Rocket Propulsion and Launch Vehicle Technology, NASA/Marshall Space Flight Center, April 2325.

Rangwalla, A. A., Madavan, N. K., and Johnson, P. D., 1992, "Application of an Unsteady Navier-Stokes Solver to Transonic Turbine Design," Journal of Propulsion and Power, Vol. 8, No. 5, pp. 1079-1086.

Roe, P. L., "Approximate Riemann Solvers, Parameter Vectors, and Difference Schemes," Journal of Computational Physics, Vol. 43, pp. 357-372. 